\title{
$\checkmark$ Research Square \\ Concerns and Quality of Life of Cancer Survivors Across the Survivorship Trajectory
}

Gek Phin Chua ( $\nabla$ ncccgp@nccs.com.sg)

National Cancer Centre Singapore https://orcid.org/0000-0002-8920-9788

\section{Quan Sing $\mathbf{N g}$}

National Cancer Centre Singapore

Hiang Khoon Tan

National Cancer Centre Singapore

Whee Sze Ong

National Cancer Centre Singapore

\section{Research article}

Keywords: Cancer Survivors, Concerns, Financial Support, Quality of Life, Survivorship, Fatigue, Pain.

Posted Date: November 26th, 2019

DOI: https://doi.org/10.21203/rs.2.14780/v2

License: (c) (1) This work is licensed under a Creative Commons Attribution 4.0 International License. Read Full License 


\section{Abstract}

Background Survivors of cancer deal with a myriad of acute, chronic, and late effects of cancer and its treatment which can linger on for decades and inadvertently affect their quality of life (QOL). The aim of this study is to determine the main concerns of survivors at various stages of the cancer survivorship and to assess whether these concerns have any effect on their QOL. Methods A cross-sectional survey was conducted on cancer survivors diagnosed with colorectal, breast, lung, gynaecological, prostate or liver cancers who were seen at the National Cancer Centre Singapore between 11 April and 12 July 2017. Eligible study participants self-completed a questionnaire adapted from the Mayo Clinic Cancer Centre's Cancer Survivors Survey of Needs.QOL was rated by participants on a scale of $0-10$, with higher ratings denoting higher level of QOL. Results A total of 1107 cancer survivors filled in the questionnaire. The top 5 concerns among all survivors were cancer treatment and recurrence risk $(51 \%)$, followed by long-term treatment effects (49\%), fear of recurrence (47\%), financial concerns $(37 \%)$ and fatigue $(37 \%)$. Cancer treatment and recurrence risk, long-term treatment effects and fear of recurrence were amongst the top concerns across the survivorship trajectory. Mean QOL was 7.3 on a scale of $0-10$. Completed treatment patients had higher QOL score than the newly diagnosed and on treatment patients and the patients dealing with recurrence or second cancer patients. Predictors for QOL included the economic status and housing type of patients and whether patients were concerned with pain and fatigue. Conclusion This study confirms that cancer survivors in Singapore face multiple challenges and had various concerns at various stages of cancer survivorship, some of which negatively affect their QOL. It is critical to design patient care delivery systems that appropriately addresstheir key concerns at different stages of their cancer trajectory so as to enhance their coping skills throughout their cancer journey.

\section{Background}

The advent of technologies in the early detection and diagnosis of cancer with better treatment modalities and care have improved the survival rates of many cancer patients [1]. There are many definitions of cancer survivors. The biomedical definition of cancer survival refers to population of cancer patients who live disease-free for at least 5 years after treatment. In contrast, the National Coalition for Cancer Survivorship (NCCS) defines it as an individual from the time of cancer diagnosis through the balance of his or her life [2].

Cancer survivors experience high level of physical, emotional, and social problems related to their cancer and treatment [3-7]. Besides the short-term adverse effects of cancer treatment, cancer treatment can also cause long-term (late) health effects. Late effects of cancer treatment include, but not limited to pain, chronic fatigue, lymphedema, peripheral neuropathy, cognitive impairment, infertility, cardiomyopathy, osteoporosis, including an increased risk of second primary cancers [8-13]. Cancer survivors also experienced persistent emotional and psychological issues relating to anxiety, depression, fears of recurrence and concerns regarding passing the disease to their offspring $[14,15]$. They also face a host of economic, financial, insurance and employment concerns $[10,15,16]$. These studies suggest that longterm consequences of cancer include not only lingering issues that present after diagnosis and treatment, 
but also new concerns that develop over time. These effects can affect day to day functioning and coping of cancer survivors and inadvertently affect their QOL. The World Health Organization (WHO) defines QOL as an individual's perception of life, goals, expectations, standards and concerns in the context of culture and value systems [17]. A number of illness-related factors can affect QOL. In the context of cancer survivors, side effects of cancer and its treatment [11,12,18], financial concerns [16,19], distress over recurrence [19], family-related distress [19] have been found to affect survivors' QOL. It is an important predictor in outcomes of the disease and its treatment [20] and one of the indicators of adjustment in cancer survivors [12]. It is therefore crucial to understand and address not only the immediate but also the long-term medical and psychosocial issues that confront cancer survivors as they transit across the survivorship trajectory in order to enhance coping skills and improve their QOL.

The importance of identifying the most salient concerns the cancer survivors are experiencing in order to guide practice is a fundamental component of patient-centered care. According to the Institute of Medicine (IOM) [21], besides effective patient education, empowerment, and communication, patientcentered care in the oncology setting also includes coordination and integration of care; and provision of emotional support as needed, such as relieving fear and anxiety and addressing mental health issues. Ascertaining the concerns of cancer survivors would aid healthcare professionals to provide survivors with timely and appropriate information and develop interventions to better address and manage these concerns. This could potentially enhance their coping skills, alleviate survivors' psychologic distress about these concerns, improve satisfaction with care delivery, and exert a positive effect on their quality of life [22,23]. Although cancer is the leading cause of morbidity and mortality in Singapore [24], however, there is no reported study with regard to the concerns of cancer survivors in Singapore. As most of the published studies on survivors' concerns were conducted outside of Singapore, the generalizability of the recommendations from these studies on how to address the survivors' concerns and improve delivery of survivorship care to the Singapore healthcare system is limited. Furthermore, small sample size [25], a focus on cancer types $[10,11,26,27]$ and age [28-30] are other limiting factors to previous studies in their application to Singapore.

The primary aim of this study is to establish the main concerns survivors of the across the cancer trajectory, and the secondary aim is to assess whether these concerns have any effect on their QOL. The overall goal was to use the insights from the study to guide practice on patient care.

\section{Methods}

\section{Study Design and Participants}

A cross-sectional survey was conducted at the specialist outpatient clinics and the clinics at the radiation oncology department in the National Cancer Centre Singapore, which sees the majority of the public sector oncology cases in Singapore [31]. All eligible patients were invited to take part in the survey during their first visit to the cancer center from 11 April to 12 July 2017. Inclusion criteria of this study were cancer survivors who were defined as individuals from the time of cancer diagnosis through the balance 
of their lifespan according to the NCCS, aged at least 21 years old, able to read and write English or Chinese, did not have major intellectual or psychiatric impairment, and diagnosed with either colorectal, breast, lung, gynaecological, prostate or liver cancer (the top 6 cancers in Singapore).

\section{Instruments}

The self-administered questionnaire used in the survey was based on the "Cancer Survivors Survey of Needs" developed by the Mayo Clinic Cancer Centre [32]. The instrument was developed based on extensive literature reviews and pilot tested. Content validity was established through review by members of the Cancer Education Network. The questionnaire was translated to Chinese and verified by two staff who were competent in both English and Chinese languages. Five domains of concerns were covered in the questionnaire viz. (1) physical (20 issues), (2) emotional (14 issues), (3) social (7 issues), (4) spiritual (4 issues), and (5) others (6 issues). The issues covered in each domain were the same as those in the original survey from the Mayo clinic, except for the additional of one issue on "Cancer treatment and recurrence risk" under the others domain. Respondents assessed the level of concern on each issue in the past 1 week prior to the survey using a 5-point Likert scale (Not concerned, Not really concerned, Neither unconcerned nor concerned, Concerned and Very concerned). The questionnaire also contained openended questions where respondents were asked to share on their primary source of strength during their cancer experience and what was their primary concern regarding their healthcare needs. In addition, respondents also rated their overall QOL in the past 1 week prior to the survey from 0 (as bad as it can be) to 10 (as good as it can be). Demographics (age, gender, ethnicity, marital status), socioeconomic (education qualification, economic status, housing type), clinical (cancer type, year since diagnosis) and treatment characteristics were also collected as part of the questionnaire.

\section{Study Procedure and Data Collection}

Prior to each patient's first clinic visit during survey period, research assistants reviewed the patient's medical records and performed pre-screening. A copy of the survey form together with an explanatory note containing detailed explanation of the study purpose and procedure on how to complete the questionnaire were attached to the patient's medical case sheet for each potential eligible patient. The clerical staff of the clinics in the cancer center confirmed the eligibility criteria of each patient and invited only those eligible ones to participate. Participation in the survey was voluntary and completion of survey form indicated patient's consent to participate in the study. A total of 1107 questionnaires were returned, and the estimated response rate was $14.3 \%$.

\section{Ethics and Consent to Participate}


Ethical consent was obtained from the SingHealth Centralised Institutional Review Board (CIRB) prior to the study. Waiver of written informed consent was obtained as no personal identifiers of respondents were obtained.

\section{Data Analysis}

Data were analysed for the study participants, and by cancer survivorship stages. The cancer survivorship stages included in these further analyses were selected and grouped based on the clinical significance and the number of patients in the stage: patients who were newly diagnosed and on treatment (NT), patients who had completed treatment or were cancer-free $\geq 5$ years (CT), and patients dealing with recurrence or second cancer (RS).

Patient characteristics at baseline were summarized as median (interquartile range) or frequency (percentage). Differences in mean QOL score between 2 groups of patients were compared using independent T-tests. Logistic regression models were fitted to assess the association of various variables with patients reporting $\geq 1$ concerned or very concerned issue. Linear regression models were fitted to identify the variables associated with QOL. Statistically significant variables with $p<0.05$ in the univariate analyses were entered into the multivariable regression analyses. Model diagnostics were performed in which spearman correlations were used to identify potential multicollinearity between independent variables. Graphical assessments were made to check linear relationship between the variables included in each model with either the log odds of patients reporting $\geq 1$ concerned or very concerned issue (for logistic model) or QOL (for linear model), as well as the normality and homoscedasticity of residuals of each linear model. All reported p-values were 2-sided, and a p-value $<0.05$ was considered statistically significant. All analyses were performed using SAS version 9.4 [33].

\section{Results}

\section{Patient Characteristics}

A total of 1107 patients filled in the survey form, of which 248 were NT (22\%), 687 were CT (62\%) and 96 were RS (8.7\%). Median age of all patients was 61 years (range, 21 - 89 years) and two-thirds was female (Table 1). Majority of the patients were married (75\%), had secondary and above qualifications (78\%), and were either employed (43\%) or retirees (34\%). Patients across the cancer survivorship stages were similar in these characteristics. The commonest cancer site was in the breast (40\%), followed by colorectal (22\%) and lung (14\%). Compared with the CT and RS patients, there were proportionately fewer breast cancers (32\% NT vs $43 \%$ CT vs $42 \%$ RS) and more lung cancers ( $22 \%$ NT vs $10 \%$ CT vs $12 \%$ RS) amongst the NT patients. 


\section{Concerns}

About $90 \%$ of the study participants reported that they had at least one issue of concern (Figure 1). Based on the study participants, the issue with the highest percentage of patients reporting that they were concerned or very concerned with was cancer treatment and risk of recurrence $(51 \%)$, followed by longterm treatment effects (49\%), fear of recurrence (FOR) (47\%), fatigue (37\%) and financial concerns (37\%) (Additional Table 1). Some of the prevalent concerns were common across the cancer survivorship stages. Cancer treatment and recurrence risk, long-term treatment effects and FOR were amongst the top 5 concerns reported by patients in each cancer survivorship stage. CT and RS patients who had received cancer treatment previously were also highly concerned with fatigue, while NT and RS patients who were either currently undergoing or going to receive treatment were highly concerned about their finances. In addition, NT and CT patients were also highly concerned with keeping their primary care physician informed of their cancer treatment and recurrence risk. When patients were broken down by various patient characteristics within each cancer survivorship stage, the most prevalent concern reported by patients in each characteristic subgroup remained largely the same as that reported by all the patients in the survivorship stage (data not shown).

\section{Risk Factors for Reporting At Least One Issue of Concern}

Risk factors for patients to report at least one issue of concern were listed in Table 2. RS patients were more likely than CT patients to report at least one issue of concern overall and in each domain. Excluding the spiritual domain, patients who had chemotherapy were also more likely to report at least one issue of concern in each of the remaining domain and overall. Notably, tumour type was not a significant predictor for presence of at least one issue of concern amongst patients in this study.

\section{Quality of Life}

The overall mean QOL score was 7.3 with a standard deviation (SD) of 2.1. CT patients had higher QOL score (mean \pm SD: $7.6 \pm 1.9)$ than the NT patients $(6.9 \pm 2.2)$ and the RS patients $(6.7 \pm 2.5)$. The mean QOL scores of patients who had concerns in each of the non-spiritual domain were significantly lower than those of their counterparts who were not concerned (Table 3). On multivariable linear regression analysis, predictors for QOL included the economic status and housing type of patients and whether patients were concerned with pain and fatigue (Table 4). Patients who had pain and fatigue concerns reported QOL scores that were about 1 point lower than those who did not have such concerns. Cancer survivorship stages were not independently associated with QOL.

\section{Discussion}


Knowledge on the concerns of cancer survivors and their effects on QOL is an important step in developing appropriate interventions to enhance coping skills and improve their QOL. In this study, we found that the top concerns of the cancer survivors were cancer treatment and the risk of recurrence, longterm treatment effects and FOR. Cancer treatment related acute and late side effects have been well reported in the literature $[3,5,8-12,14,15]$. It has also been reported that even 20 years after stopping cancer treatment, the risks of recurrence (distant or contralateral breast) was present [34]. In our study, FOR was the top emotional concern among the cancer survivors and also throughout the cancer trajectory. This finding has also been reported by other studies [14,25,35-40]. Evidence in literature reveals the negative impacts associated with FOR, including emotional distress [41], functional status [42] and QOL [42-44]. Unlike other studies, we find that higher FOR is not associated with poorer QOL of survivors. A recent study by Cho and Park [45] on 292 adolescent and young adult cancer survivors found that the negative association between FOR and mental health-related quality of life (HRQOL) was moderated by perceived growth (such as relating to others, personal growth, new possibilities, appreciation of life and spiritual life). In view of the moderating effects of perceived growth on the FOR-HRQOL links, enhancing on the growth perception may also be an strategy worth considering. As our study only measured the respondents' overall QOL and we did not measure the perceived growth, this finding warrants further study.

Financial concerns were amongst the top concerns for patients who were either undergoing or about to undergo treatment in this study. We also found that those with lower economic status including those staying in public Housing Development Board (HDB) flats are at higher risk of poorer QOL. As demonstrated in other studies, financial burden of cancer treatment is high and respondents expressed a great deal of worry about financial matters $[40,47,48]$. Evidence $[48]$ also indicates that increased financial burden as a result of cancer care costs is the strongest independent predictor of poor QOL and adverse psychological issues such as depression, anxiety, and distress $[48,49]$ among cancer survivors. As QOL is negatively affected by financial burden, early identification of at risk patients and referrals to financial support services may help lessen this concern. At the state level, efforts to manage the escalating cost of cancer treatment, provision of better financial coverage and support and addressing the aspect of unemployment of cancer patients would be needed.

Fatigue was the most prevalent physical concern and one of the predictors for QOL in this study. Cancerrelated fatigue is a well-established concern for cancer survivors [8,36,39,40,50]. Fatigue reduces QOL by affecting a patient's self-concept, appetite, activities of daily living, employment, social relationships and compliance with medical treatment $[8,18,39,50]$, and may lead to treatment discontinuation and reduced survival [51]. Our study also found that fatigue was a major concern of the longer term cancer survivors which suggested that fatigue might have some lingering effect after cancer treatment. Bower's [51] review suggests that approximately slightly more than a quarter cancer survivors experienced persistent fatigue through 10 years after cancer diagnosis and that is underreported by patients and undertreated by clinicians. Besides fatigue, our study also found that patients who had physical concerns of pain had poorer QOL. In addition, one of the risk factors for having $\geq 1$ physical concern was whether patient had chemotherapy. Our findings are consistent with other studies. For instance, Heydarnejad et al. [18] found 
that QOL of patients undergoing chemotherapy was lower in patients with pain than to those who had no pain and pain was found to be the strongest predictor of fatigue, Fatigue can be caused by pain [50]. This may potentially revealed a symptom cluster (i.e., two or more concurrent symptoms that are related and may or may not have a common cause) [52] that warrants more in-depth study to closely examine if there is any relationship between these symptoms. Knowledge of whether these symptoms are interrelated within a cluster might therefore help manage these symptoms more effectively and thus lessen the total symptom burden.

Significant difference in QOL was also found between patients who were concerned with the most prevalent issue and those who were not for the NT and RS patients, but not the CT patients (Additional Table 2). It is not surprising that NT and RS patients' QOL is more significantly affected as these are vulnerable times in the survivorship trajectory and the psychological distress confronting them is well reported in the literature $[4,53,54]$.

Based on current evidence, cancer treatment with its inherent side effects and whether it is efficacious, FOR, financial concerns and fatigue are the most distressing concerns with some of these concerns affecting their QOL in cancer patients throughout their cancer trajectory warrant the monitoring of these acute and long-term effects across the entire cancer trajectory for clinical identification of patients who might benefit from enhanced medical attention resulting in an improved QOL. They also underscore the importance of creating an information and supportive care environment that addresses survivors' information needs and emotional support over time. This could also include assessments for symptoms and distress, and the adoption of the use of survivorship care plans (SCPs) [55,56]. SCPs have been recommended by the IOM [57] as a tool to assist cancer survivors transit from cancer treatment to followup care through educating survivors and providers with comprehensive health information and resources [56]. This would also potentially address their concern about the integration of survivorship care between oncology and primary care settings. This is critical as well informed and supported patients have been associated with many positive outcomes, including, increased patient involvement in decision making, increased satisfaction with treatment decisions, enhanced coping during the diagnostic, treatment and post treatment phases of illness, decreased anxiety and mood disturbances, and less emotional distress $[22,23,27,58,59]$.

\section{Limitations}

There are several limitations in this cross-sectional survey, which collected data on the perceived concerns from a selective group of cancer survivors at a specific point in time in their survivorship trajectory using a non-validated questionnaire for the study population. Longitudinal studies of cancer survivors' needs and their concerns throughout their survivorship trajectory would provide more complete insights on the changes in concerns at different times in the continuum of care. Identifying the ongoing and changing concerns of cancer survivors especially as they transit away from the treatment phase remains a key challenge for survivorship study. To partly overcome this limitation, we analysed the survey data 
according to key time points of cancer survivorship such as during treatment, treatment completion and recurrence instead of variable such as time since cancer diagnosis

The study sample included only patients diagnosed with colorectal, breast, lung, gynaecological, prostate or liver cancer from a single cancer centre, and this might limit the generalization of the results to other settings. There were also proportionately more breast cancer survivors who participated in the survey, which suggested that the data might underrepresent the concerns of cancer survivors with the other cancer types. To limit these effects, we reported the survey results based on the overall cohort and by cancer survivorship stages instead of breaking down the analyses by cancer sites.

Another study limitation is the low survey response rate at $14.3 \%$. This response rate is, however, an under-estimate because it is calculated based on the total number of questionnaires attached to the medical case sheet of potential study participants instead of the total number of questionnaires distributed to confirmed eligible patients. Due to some oversight in survey operations, the latter is not tracked in this study. With a low response rate, results from this survey could be affected by non-response bias. Unfortunately, we are unable to assess the extent of non-response bias or adjust the survey estimates for non-response via weighting. This is because we are unable to identify who are the nonrespondents in the survey, as there are no personal identifiers collected in the questionnaire that we could use to identify the respondents who have returned the survey form. Given this, the results from this survey must be interpreted with caution.

In spite of these limitations, given the large sample of the top 6 most common cancers in Singapore, we believe that our study has added valuable insights on the concerns of cancer survivors treated in an Asian cancer centre. It also helped prioritized which are the concerns that should be the focus of prevention and remediation efforts in our patient care delivery. To our knowledge, this is the first study determining the concerns of cancer survivors in Singapore.

\section{Conclusions}

The study concludes that cancer survivors in Singapore face multiple challenges and had various concerns at various stages of cancer survivorship, some of which negatively affect their QOL. As betterinformed patients are more able to cope, more satisfied with their care and do better clinically, it is critical that sufficient resources be allocated to develop appropriate strategies to address the key areas of concerns of cancer survivors. Important areas to address include symptom assessments and management, adoption of distress screening tools at each transition of survivorship trajectory, and development of education materials and psychosocial support services relating to the various identified concerns so as to enhance coping skills and improve their quality of life, with the main ones being the long-term effects of cancer treatment, risks of cancer recurrence, fatigue, and financial support and resources.

Another strategy worth considering is the adoption of the SCP which is highly recommended by the IOM. Such care plans could potentially enable the survivors to play an active role in the management of long- 
term effects of their cancers and provide an effective communication tool for their primary healthcare providers to provide appropriate care to these survivors. Finally, a periodic audit of the concerns of survivors and how well their needs are met should be conducted under a patient-centered approach in understanding and addressing the unique and evolving concerns of cancer survivors across the survivorship trajectory.

\section{Abbreviations}

NCCS: National Coalition for Cancer Survivorship; QOL: Quality of Life; NT: Newly diagnosed and on treatment; CT: Completed treatment or were cancer-free $\geq 5$ years; RS: Recurrence or second cancer; SD: Standard deviation; FOR: Fear of recurrence; HRQOL: Health-related Quality of Life; SCP: Survivorship Care Plan; IOM: Institute of Medicine.

\section{Declarations}

\section{Acknowledgements}

This study was supported by a grant from the National Cancer Centre Research Fund (NCCRF-YR2016JUL-PG3). We express appreciation to the patients who participated in this research. Special thanks to nurses and clerical staff for their invaluable contributions.

\section{Authors' contributions}

CGP conceptualised and designed the study. Data collection was managed by CGP. OWS performed data cleaning and statistical analysis. NQS and THK supervised and provided guidance and expertise. All authors read and approved the final manuscript.

\section{Funding}

This study was supported by a grant from the National Cancer Centre Research Fund (NCCRF-YR2016JUL-PG3).

\section{Availability of data and materials}

All data supporting the findings of this study are available within the article.

\section{Ethics approval and consent to participate}

Ethical consent was obtained from the SingHealth Centralised Institutional Review Board (CIRB) prior to the study. Waiver of written informed consent was obtained as no personal identifiers of respondents were obtained.

\section{Consent for Publication}


Not applicable.

\section{Competing Interest}

The authors have no conflict of interest to declare.

\section{References}

1. Stein KD, Syrjala KL, Andrykowski MA. Physical and psychological long-term and late effects of cancer. Cancer Supplement. 2008;112(11):2577-92.

2. National Coalition for Cancer Survivorship (NCCS). Our Mission. 2008. https://www.canceradvocacy.org/about-us/our-mission/. Accessed 20 Sept 2018.

3. Chan HK, Ismail S. Side effects of chemotherapy among cancer patients in a Malaysian General Hospital: experiences, perceptions and information needs from clinical pharmacists. Asian Pac J Cancer Prev. 2014;15:5305-9.

4. Farpour HR, Habibi L, Owji SH. Positive impact of social media use on depression in cancer patients. Asian Pac J Cancer Prev. 2017;18(11):2985-8.

5. Pearce A, Haas M, Viney R, Pearson SA, Haywood P, Brown C, Ward R. Incidence and severity of selfreported chemotherapy side effects in routine care: a prospective cohort study. PLoS One. 2017;12:112.

6. Solheim TS, Blum D, Fayers PM, Hjermstad MJ, Stene GB, Strasser F, Kaasa S. Weight loss, appetite loss and food intake in cancer patients with cancer cachexia: three peas in a pod? - analysis from a multicentre cross sectional study. Acta Oncologica. 2014;53(4):539-46.

7. Trill MD. Psychological aspects of depression in cancer patients: an update. Annals of Oncology. 2012;23(Suppl 10):x302-5.

8. Kuhnt S, Ernst J, Singer S, Ruffer JU, Kortmann RD, Stolzenburg JU, Schwarz R. Fatigue in cancer survivors - prevalence and correlates. Onkologie. 2009;32:312-7.

9. Howard-Anderson J, Ganz PA, Bower JE, Stanton AL. Quality of life, fertility concerns, and behavioural health outcomes in younger breast cancer survivors: a systematic review. J Natl Cancer Inst. 2012;104:386-405.

10. Kim YA, Yun YH, Chang YJ, Lee J, Kim MS, Lee HS, Zo JI, Kim J, Choi YS, Shim YM, Yoon SJ. Employment status and work-related difficulties in lung cancer survivors compared with the general population. Annals of Surgery. 2014;259:569-75.

11. Ochayon L, Zelker R, Kaduri L, Kadmon I. Relationship between severity of symptoms and quality of life in patients with breast cancer receiving adjuvant hormonal therapy. Oncology Nursing Forum. 2010;37:349-58.

12. Yang P, Cheville AL, Wampfler, Garces YI, Jatoi A, Clark MM, Cassivi SD, Midthun DE, Marks RS, Aubry MC, Okuno SH, Williams BA, Nichols FC, Trastek VF, Sugimura H, Sarna L, Allen MS, Deschamps C, 
Sloan JA. Quality of life and symptom burden among long-term lung cancer survivors. J Thorac Oncol. 2012;7:64-70.

13. Zucca AC, Boyes AW, Linden W, Girgis A. All's well that ends well? Quality of life and physical symptom clusters in long-term cancer survivors across cancer types. Journal of Pain and Symptom Management. 2012;43(4):720-31.

14. Tan ASL, Nagler RH, Hornik RC, DeMichele A. Evolving information needs among colon, breast, and prostate cancer survivors: results from a longitudinal mixed-effects analysis. Cancer Epidemiology Biomarkers Prev. 2015;24:1071-8.

15. Wilson SE, Anderson MR, Meischke H. Meeting the needs of rural breast cancer survivors: what still needs to be done? Journal of Women's Health and Gender-Based Medicine. 2000;9:667.

16. Kale HP, Carroll NV. Self-reported financial burden of cancer care and its effect on physical and mental health-related quality of life among US cancer survivors. Cancer 2016;122:1283-9.

17. World Health Organisation (WHO). WHOQOL: Measuring quality of life. 2019. https://www.who.int/healthinfo/survey/whoqol-qualityoflife/en. Accessed 13 Nov 2019.

18. Heydarnejad MS, Dehkordi H, Dehkordi SK. Factors affecting quality of life in cancer patients undergoing chemotherapy. African Health Sciences. 2011;11:266-70.

19. Avis NE, Crawford S, Manuel J. Quality of life among younger women with breast cancer. Journal of Clinical Oncology. 2005;23(15):3324-30.

20. Yun YH, Kim YA, Sim JA, Shin AS, Chang YJ, Lee J, Kim MS, Shim YM, Zo JI. Prognostic value of quality of life score in disease-free survivors of surgically-treated lung cancer. BMC Cancer. 2016;16:505.

21. Institute of Medicine (IOM). Patient-centered communication and shared decision making. In: Levit LA, Balogh EP, Nass SJ, Ganz PA, editors. Delivering High-Quality of Cancer Care: Charting a New Course for A System in Crisis. Washington: The National Academies Press; 2013.

22. Hesse BW, Arora NK, Beckjord EB, Rutten LJF. Information support for cancer survivors. Cancer Supplement. 2008;112(11):2529-40.

23. Husson $\mathrm{O}$, Mols F, van de Poll-Franse LV. The relation between information provision and healthrelated quality of life, anxiety and depression among cancer survivors: a systematic review. Ann Oncol. 2011;22(4):761-72.

24. Ministry of Health (MOH). Principle causes of death. 2018. https://www.moh.gov.sg/resourcesstatistics/singapore-health-facts/principal-causes-of-death. Accessed 20 Sept 2018.

25. Mollica M, Nemeth L. Transition from patient to survivor in African American breast cancer survivors. Cancer Nurs. 2015;38:16-22.

26. Hodgkinson K, Butow P, Hunt GE, Pendlebury S, Hobbs KM, Wain G. Breast cancer survivors' supportive care needs 2-10 years after diagnosis. Support Care Cancer. 2007;15:515-23.

27. Miyashita M, Ohno S, Kataoka A, Tokunaga E, Masuda N, Shien T, Kawabata K, Takahashi M. Unmet informational needs and quality of life in young breast cancer survivors in Japan. Cancer Nurs. 2015;38(6):E1-11. 
28. Hauken MA, Larsen TMB, Holsen I. Meeting reality: young adult cancer survivors' experiences of reentering everyday life after cancer treatment. Cancer Nurs. 2013;36(5):E17-26.

29. Stanton AL, Rowland JH, Ganz PA. Life after diagnosis and treatment of cancer in adulthood: contributions from psychosocial oncology research. American Psychologist. 2015;70(2):159-74.

30. Zebrack B. Information and service needs for young adult cancer survivors. Support Care Cancer. 2009;17:349-57.

31. National Cancer Centre Singapore. Director's message. 2017. https://www.nccs.com.sg/AboutUs/DirectorMessage/Pages/Home.aspx. Accessed 16 Jun 2017.

32. Mayo Clinic Cancer Center. Cancer Survivors Survey of Needs. 2016. http://prc.coh.org/Survivorship/MAYO\%20CSS.pdf. Accessed 28 Sept 2016.

33. SAS Institute Inc. SAS version 9.4. 2018. https://www.sas.com/en_sg/home.html. Accessed 20 Sept 2018.

34. Pan HC, Gray R, Braybrooke J, Davies C, Taylor C, McGale P, Peto R, Pritchard KI, Bergh J, Dowsett M, Hayes DF. 20-year risks of breast-cancer recurrence after stopping endocrine therapy at 5 years. N Engl J Med. 2012;377:1836-56.

35. Cupit-Link M, Syrjala KL, Hashmi SK. Damocles' syndrome revisited: update on the fear of cancer recurrence in the complex world of today's treatments and survivorship. Hematol Oncol Stem Cell Ther. 2018;11:129-34.

36. Cutshall SM, Cha SS, Ness SM, Stan DL, Christensen SA, Bhagra A, Price KA, Thompson CA, Hashmi SK, Chon TY, McCray TJ, Sood A, Bauer BA, Ruddy KJ. Symptom burden and integrative medicine in cancer survivorship. Support Care Cancer. 2015;23:2989-94.

37. Koch $L$, Jansen $L$, Brenner $H$, Arndt V. Fear of recurrence and disease progression in long-term ( $\geq 5$ years) cancer survivors - a systematic review of quantitative studies. Psycho-Oncology. 2013;22:111.

38. Mazanec SR, Gallagher P, Miano WR, Sattar A, Daly BJ. Comprehensive assessment of cancer survivors' concerns to inform program development. JCSO. 2017;15:155-62.

39. Ness S, Kokal J, Fee-Schroeder K, Novotny P, Satele D, Barton D. Concerns across the survivorship trajectory: results from a survey of cancer survivors. Oncology Nursing Forum. 2013;40:35-42.

40. Stanton M, Franco G, Scoggins R. Case management needs of older and elderly cancer survivors. Professional Case Management. 2011;17:61-9.

41. Jimenez RB, Perez GK, Rabin J, Hall D, Quain K, Park E, Peppercorn JM. Fear of recurrence among cancer survivors. Journal of Clinical Oncology. 2017;35:10053.

42. Sarkar S, Scherwath A, Schirmer L, Schulz-Kindermann F, Neumann K, Kruse M, Dinkel A, Kunze S, Balck F, Kroger N, Koch U, Mehnert A. Fear of recurrence and its impact on quality of life in patients with hematological cancers in the course of allogeneic hematopoietic SCT. Bone Marrow Transplant. 2014;49:1217-22.

43. Kim Y, Carver CS, Spillers RL, Love-Ghaffari M, Kaw CK. Dyadic effects of fear of recurrence on the quality of life of cancer survivors and their caregivers. Qual Life Res. 2012;21:517-25. 
44. Petzel MQB, Parker NH, Valentine AD, Simard S, Gonzalez GMN, Fleming JB, Lee JE, Pisters PWT, Vauthey JN, Katz MHG. Fear of cancer recurrence and quality of life among survivors of pancreatic and periampullary neoplasms. Journal of Clinical Oncology. 2012;30:289.

45. Cho D, Park CL. Moderating effects of perceived growth on the association between fear of cancer recurrence and health-related quality of life among adolescent and young adult cancer survivors. Journal of Psychosocial Oncology. 2017;35:148-65.

46. Sherwood PR, Donovan HS, Rosenzweig M, Hamilton R, Bender CM. A house of cards: the impact of treatment costs on women with breast and ovarian cancer. Cancer Nurs. 2008;31:470-7.

47. Veenstra CM, Regenbogen SE, Hawley ST, Griggs JJ, Banerjee M, Kato I, Ward KC, Morris AM. A composite measure of personal financial burden among patients with stage III colorectal cancer. Medical Care. 2014;52:957-62.

48. Fenn KM, Evans SB, McCorkle R, DiGiovanna MP, Pusztai L, Sanft T, Hofstatter EW, Killelea BK, Knobf MT, Lannin DR, Abu-Khalaf M, Horowitz NR, Chagpar AB. Impact of financial burden of cancer on survivors' quality of life. Journal of Oncology Practice. 2014;10:332-8.

49. Sharp L, Carsin AE, Timmons A. Association between cancer-related financial stress and strain and psychological well-being among individuals living with cancer. Psycho-Oncology. 2013;22:745-55.

50. Bower JE, Ganz PA, Desmond KA, Rowland JH, Meyerowitz BE, Belin TR. Fatigue in breast cancer survivors: occurrence, correlates, and impact on quality of life. Journal of Clinical Oncology. 2000;18:743-53.

51. Bower JE. Cancer-related fatigue-mechanisms, risk factors, and treatments. Nat Rev Clin Oncol. 2014;11:597-609.

52. Fan G, Filipczak L, Chow E. Symptom clusters in cancer patients: a review of literature. Current Oncology. 2007;14:173-9.

53. Katowa-Mukwato P, Lonia M, Margaret MC, Mutinta MC, Beauty NL. Stress and coping with cervical cancer by patients: a qualitative inquiry. In J Psychol Couns. 2015;7(6):94-105.

54. Kushwaha GS. A study of seeking guidance and support coping strategy of cancer patients. Int J Psychol Couns. 2014;6(5):66-73.

55. Birken SA, Mayer DK, Weiner BJ. Survivorship care plans: prevalence and barriers to use. J Cancer Edu. 2013;28:290-6.

56. van de Poll-Franse LV, Nicolaije KAH, Ezendam NPM. The impact of cancer survivorship care plans on patient and health care provider outcomes: a current perspective. Acta Oncologica. 2017;56:134-8.

57. Institute of Medicine (IOM). From Cancer Patient to Cancer Survivor: Lost in Transition. Washington: The National Academies Press; 2006.

58. Li PWC, So WKW, Fong DYT, Lui LYY, Lo JCK, Lau SF. The information needs of breast cancer patients in Hong Kong and their levels of satisfaction with the provision of information. Cancer Nurs. 2011;34(1):49-57.

59. Lo AC, Olson R, Feldman-Stewart D, Truong PT, Aquino-Parsons C, Bottorff JL, Carolan H. A patientcentered approach to evaluate the information needs of women with ductal carcinoma in situ. Am $\mathrm{J}$ 
Clin Oncol. 2017;40(6):574-81.

\section{Tables}

Table 1. Patient characteristics by cancer survivorship stage 


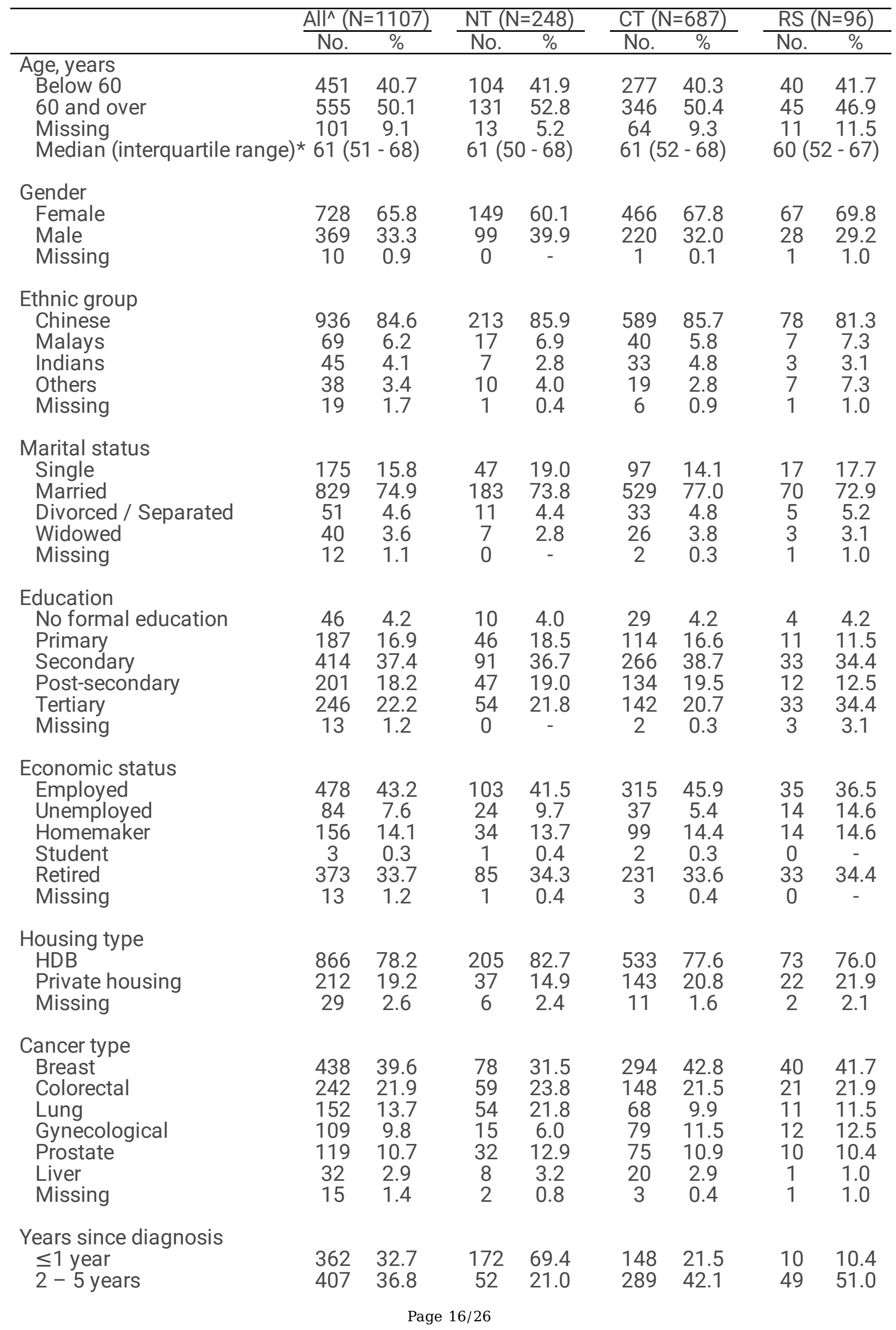




\begin{tabular}{lcccccccc} 
Z6 years & 245 & 22.1 & 0 & - & 200 & 29.1 & 34 & 35.4 \\
$\begin{array}{l}\text { Missing } \\
\text { Median (interquartile range)* }\end{array}$ & 23 & 8.4 & 24 & 9.7 & 50 & 7.3 & 3 & 3.1 \\
$\begin{array}{l}\text { Treatment received } \\
\quad \text { Surgery }\end{array}$ & 781 & 70.6 & 126 & 50.8 & 544 & 79.2 & 74 & 77.1 \\
Radiation & 563 & 50.9 & 89 & 35.9 & 407 & 59.2 & 44 & 45.8 \\
Chemotherapy & 727 & 65.7 & 189 & 76.2 & 430 & 62.6 & 72 & 75.0 \\
Hormonal therapy & 159 & 14.4 & 51 & 20.6 & 83 & 12.1 & 19 & 19.8 \\
Others & 36 & 3.3 & 18 & 7.3 & 14 & 2.0 & 0 & - \\
\hline
\end{tabular}

NT, newly diagnosed, on treatment; CT, completed treatment / cancer-free $\geq 5$ years; RS, had recurrence / second cancer

$\wedge$ Includes patients on palliative care

* Among patients with non-missing values

Table 2. Multivariable logistic regression for the presence of at least one issue of concern in domain 


\begin{tabular}{|c|c|c|c|c|}
\hline \multirow[t]{2}{*}{$\begin{array}{l}\text { Domain } \\
\text { Overall }\end{array}$} & $\begin{array}{l}\text { Variables } \\
\text { Cancer survivorship stages }\end{array}$ & $\begin{array}{l}\text { Categories } \\
\text { CT vs RS } \\
\text { NT vs RS } \\
\text { Others vs RS }\end{array}$ & $\begin{array}{c}\text { OR }(95 \% \mathrm{Cl}) \\
0.23(0.11-0.51) \\
2.77(0.34-22.85) \\
0.33(0.10-1.11)\end{array}$ & $\frac{p \text {-value }}{<0.001}$ \\
\hline & Chemotherapy & No vs Yes & $0.46(0.30-0.70)$ & $<0.001$ \\
\hline \multirow[t]{3}{*}{ Physical } & Years since diagnosis & $\begin{array}{l}\leq 1 \text { year } v s \geq 6 \text { years } \\
2-5 \text { years vs } \geq 6 \text { years }\end{array}$ & $\begin{array}{l}1.85(1.20-2.85) \\
1.30(0.90-1.86)\end{array}$ & 0.020 \\
\hline & Cancer survivorship stages & $\begin{array}{l}\text { CT vs RS } \\
\text { NT vs RS } \\
\text { Others vs RS }\end{array}$ & $\begin{array}{l}0.49(0.31-0.78) \\
1.29(0.61-2.73) \\
0.85(0.36-2.01)\end{array}$ & 0.001 \\
\hline & Chemotherapy & No vs Yes & $0.55(0.41-0.75)$ & $<0.001$ \\
\hline \multirow[t]{3}{*}{ Emotional } & Cancer survivorship stages & $\begin{array}{l}\text { CT vs RS } \\
\text { NT vs RS } \\
\text { Others vs RS }\end{array}$ & $\begin{array}{c}0.60(0.42-0.86) \\
1.77(0.91-3.44) \\
0781(0.40-1.53)\end{array}$ & 0.001 \\
\hline & Surgery & No vs Yes & $0.73(0.53-0.99)$ & 0.042 \\
\hline & Chemotherapy & No vs Yes & $0.55(0.42-0.73)$ & $<0.001$ \\
\hline \multirow[t]{3}{*}{ Social } & Age & per year increase & $0.98(0.97-0.99)$ & $<0.001$ \\
\hline & Cancer survivorship stages & $\begin{array}{l}\text { CT vs RS } \\
\text { NT vs RS } \\
\text { Others vs RS }\end{array}$ & $\begin{array}{l}0.55(0.40-0.76) \\
1.39(0.80-2.42) \\
2.14(1.02-4.49)\end{array}$ & $<0.001$ \\
\hline & Chemotherapy & No vs Yes & $0.67(0.50-0.88)$ & 0.005 \\
\hline \multirow[t]{3}{*}{ Spiritual } & Gender & Female vs Male & $1.61(1.16-2.21)$ & 0.004 \\
\hline & Race & $\begin{array}{l}\text { Malay vs Chinese } \\
\text { Indian vs Chinese } \\
\text { Others vs Chinese }\end{array}$ & $\begin{array}{l}3.67(2.19-6.16) \\
2.18(1.14-4.18) \\
1.53(0.70-3.35)\end{array}$ & $<0.001$ \\
\hline & Cancer survivorship stages & $\begin{array}{l}\text { CT vs RS } \\
\text { NT vs RS } \\
\text { Others vs RS }\end{array}$ & $\begin{array}{l}0.61(0.43-0.87) \\
1.45(0.86-2.45) \\
1.76(0.90-3.42)\end{array}$ & $<0.001$ \\
\hline \multirow[t]{2}{*}{ Others } & Cancer survivorship stages & $\begin{array}{l}\text { CT vs RS } \\
\text { NT vs RS } \\
\text { Others vs RS }\end{array}$ & $\begin{array}{l}0.51(0.36-0.72) \\
1.03(0.57-1.87) \\
1.77(0.74-4.20)\end{array}$ & $<0.001$ \\
\hline & Chemotherapy & No vs Yes & $0.68(0.51-0.90)$ & 0.007 \\
\hline
\end{tabular}

$\mathrm{OR}$, odds ratio; $\mathrm{Cl}$, confidence interval; NT, newly diagnosed, on treatment; $\mathrm{CT}$, completed treatment / cancer-free $\geq 5$ years; RS, had recurrence / second cancer 
Table 3. Comparison of QOL scores by whether patients had at least one issue of concern in domain and cancer survivorship stage

\begin{tabular}{|c|c|c|c|c|c|c|c|c|c|}
\hline \multirow{3}{*}{ Domain } & \multicolumn{3}{|c|}{$\mathrm{All}^{\wedge}(\mathrm{N}=1107)$} & \multicolumn{3}{|c|}{ NT $(N=248)$} & \multicolumn{2}{|l|}{$\mathrm{CT}(\mathrm{N}=687)$} & $\mathrm{RS}(\mathrm{N}=96)$ \\
\hline & $\mathrm{C}$ & $\mathrm{NC}$ & & $\mathrm{C}$ & $\mathrm{NC}$ & & C $\quad \mathrm{NC}$ & & $\mathrm{C} \quad \mathrm{NC}$ \\
\hline & $\begin{array}{l}\text { Mean } \\
\text { (SD) }\end{array}$ & $\begin{array}{l}\text { Mean } \\
\text { (SD) }\end{array}$ & diff & $\begin{array}{l}\text { Mean } \\
\text { (SD) }\end{array}$ & $\begin{array}{l}\text { Mean } \\
\text { (SD) }\end{array}$ & diff & $\begin{array}{cc}\text { Mean } & \text { Mean } \\
(\mathrm{SD}) & (\mathrm{SD})\end{array}$ & diff & $\begin{array}{cc}\text { Mean } & \text { Mean } \\
\text { (SD) } & \text { (SD) }\end{array}$ \\
\hline Physical & $\begin{array}{c}7.0 \\
(2.1)\end{array}$ & $\begin{array}{c}8.3 \\
(1.5)\end{array}$ & $1.3^{\star \star \star}$ & $\begin{array}{l}6.7 \\
(2.2)\end{array}$ & $7.8(1.7)$ & $1.1^{\star \star}$ & $7.3(1.9) 8.4(1.4)$ & $1.1^{\star \star \star}$ & $6.4(2.5) 8.3(1.3) 1.9^{\star \star}$ \\
\hline Emotional & $\begin{array}{l}7.0 \\
(2.11\end{array}$ & $\begin{array}{l}8.0 \\
(18)\end{array}$ & $1.0 *$ & $\begin{array}{l}6.5 \\
(2.3)\end{array}$ & $7.7(1.6)$ & $1.2^{\star \star \star}$ & $7.4(1.9) 8.1(1.7)$ & $0.7 \star \star \star$ & $6.4(2.5) 8.0$ (2.1) 1.6* \\
\hline Social & $\begin{array}{l}6.9 \\
(22)\end{array}$ & $\begin{array}{l}7.8 \\
(18)\end{array}$ & $0.9 \star \star \star$ & $\begin{array}{l}6.5 \\
(2.5)\end{array}$ & $7.5(2.0)$ & $1.0 \star \star$ & $7.2(2.0) 7.9(1.7)$ & $0.7 \star \star \star$ & $6.5(2.7) 7.2(1.9) 0.7$ \\
\hline Spiritual & $\begin{array}{l}7.1 \\
(23)\end{array}$ & $\begin{array}{l}7.3 \\
(20)\end{array}$ & 0.2 & $\begin{array}{c}6.9 \\
(2.3)\end{array}$ & $6.9(2.1)$ & & $7.5(2.1) 7.6(1.8)$ & 0.1 & $6.3(3.0) 6.9$ (2.2) 0.6 \\
\hline Others & $\begin{array}{l}7.1 \\
(2.1)\end{array}$ & $\begin{array}{l}7.8 \\
(1.8)\end{array}$ & $0.7^{\star \star \star}$ & $\begin{array}{l}6.7 \\
(2.3)\end{array}$ & $7.4(1.6)$ & $0.7 * \star$ & $7.4(1.9) 7.9$ (1. & $0.5^{\star \star}$ & 6.5 (2.6)7.3 (2.0) 0.8 \\
\hline
\end{tabular}

QOL, quality of life; SD, standard deviation; NT, newly diagnosed, on treatment; CT, completed treatment / cancer-free $\geq 5$ years; RS, had recurrence / second cancer; $C$, patients with at least one issue of concern in domain; NC, patients with no issue of concern in domain

${ }^{\wedge}$ Includes patients on palliative care

$\star 0.01 \leq p<0.05 \quad * * 0.001 \leq p<0.01 \quad * \star * p<0.001$

Table 4. Multivariable linear regression for QOL score

\begin{tabular}{llcc}
\hline Variable & Categories & Beta estimate $(\mathrm{SE})$ & p-value \\
\hline Constant & - & $8.25(0.16)$ & $<0.001$ \\
Economic status & Employed vs Retired & $0.34(0.14)$ & 0.015 \\
& Unemployed vs Retired & $-0.37(0.25)$ & 0.134 \\
& Homemaker vs Retired & $0.57(0.20)$ & 0.004 \\
Housing & HDB vs Private housing & $-0.61(0.16)$ & $<0.001$ \\
Physical issue: Pain & C vs NC & $-0.88(0.15)$ & $<0.001$ \\
Physical issue: Fatigue & C vs NC & $-1.07(0.14)$ & $<0.001$ \\
\hline
\end{tabular}

QOL, quality of life; SE, standard error; C, concerned or very concerned with issue; NC, not concerned, not really concerned or neither concerned nor unconcerned with issue

^ Excludes 3 students from analysis as this small category of patients cannot be combined with the other categories of economic status appropriately

\section{Additional Tables}


Additional Table 1. Patients who were concerned or very concerned on each issue of concern by cancer survivorship stage 


\begin{tabular}{|c|c|c|c|c|c|c|c|c|}
\hline \multirow[t]{2}{*}{ Issue } & \multicolumn{2}{|c|}{ All^ $(\mathrm{N}=1107)$} & \multicolumn{2}{|c|}{$\mathrm{NT}(\mathrm{N}=248)$} & \multicolumn{2}{|c|}{$\mathrm{CT}(\mathrm{N}=687)$} & \multicolumn{2}{|c|}{$\mathrm{RS}(\mathrm{N}=96)$} \\
\hline & & & No. (\%) & rank & No. (\%) & rank & $\begin{array}{l}\text { No. } \\
(\%)\end{array}$ & rank \\
\hline 1 Physical & & & & & & & & \\
\hline & $\begin{array}{c}317 \\
(28.6)\end{array}$ & $13^{*}$ & $\begin{array}{c}70 \\
(28.2)\end{array}$ & 20 & $\begin{array}{c}174 \\
(25.3)\end{array}$ & 12 & $\begin{array}{c}43 \\
(44.8)\end{array}$ & 9 \\
\hline 1.02 Fatigue & $\begin{array}{c}413 \\
(37.3)\end{array}$ & 4 & $\begin{array}{c}98 \\
(39.5)\end{array}$ & 6 & $\begin{array}{l}224 \\
(32.6)\end{array}$ & 4 & $\begin{array}{c}52 \\
(54.2)\end{array}$ & 4 \\
\hline 1.03 Sleep disturbances & 356 & 8 & $\begin{array}{c}85 \\
(343)\end{array}$ & 12 & $\begin{array}{l}188 \\
(274)\end{array}$ & 10 & $\begin{array}{c}44 \\
(458)\end{array}$ & 6* \\
\hline 1.04 Memory and concentration & $\begin{array}{l}271 \\
(245)\end{array}$ & 24 & $\begin{array}{c}63 \\
(25.4)\end{array}$ & $28^{*}$ & $\begin{array}{c}150 \\
(218)\end{array}$ & 18 & $\begin{array}{l}36 \\
(375)\end{array}$ & $19 *$ \\
\hline 1.05 Nausea / Vomiting & 155 & 41 & $\begin{array}{c}49 \\
(198)\end{array}$ & $36 *$ & $60(8.7)$ & 44 & 25 & $37 *$ \\
\hline 1.06 Poor appetite & $\begin{array}{l}162 \\
(146)\end{array}$ & 40 & $\begin{array}{c}49 \\
(198)\end{array}$ & $36 *$ & $\begin{array}{c}75 \\
(109)\end{array}$ & 41 & 21 & 42 \\
\hline 1.07 Trouble swallowing & $\begin{array}{l}108 \\
(9.8)\end{array}$ & 46 & 27 & 46 & $54(7.9)$ & 46 & $\begin{array}{c}19 \\
(198)\end{array}$ & 44 \\
\hline 1.08 Dental and mouth problems & $\begin{array}{c}177 \\
(16.0)\end{array}$ & 39 & $\begin{array}{c}45 \\
(18,1)\end{array}$ & $40^{*}$ & $\begin{array}{c}96 \\
(14.0)\end{array}$ & 35 & $\begin{array}{c}25 \\
(260)\end{array}$ & $37 *$ \\
\hline 1.09 Weight changes & $\begin{array}{c}275 \\
(248)\end{array}$ & 22 & $\begin{array}{l}74 \\
(298)\end{array}$ & $17 *$ & $\begin{array}{c}143 \\
(208)\end{array}$ & 21 & $\begin{array}{c}39 \\
(406)\end{array}$ & $13^{*}$ \\
\hline 1.10 Balance / Walking / Mobility & $\begin{array}{l}263 \\
(23.8)\end{array}$ & 26 & $\begin{array}{c}64 \\
(25.8)\end{array}$ & $25^{\star}$ & $\begin{array}{c}145 \\
(21.1)\end{array}$ & $19 *$ & $\begin{array}{c}33 \\
(34.4)\end{array}$ & 29 \\
\hline 1.11 Loss of strength & $\begin{array}{l}374 \\
(33.8)\end{array}$ & 7 & $\begin{array}{c}97 \\
(39.1)\end{array}$ & 7 & $\begin{array}{l}203 \\
(29.5)\end{array}$ & 7 & $\begin{array}{c}40 \\
(41.7)\end{array}$ & 11 * \\
\hline $\begin{array}{l}1.12 \text { Tingling and numbness in feet and } \\
\text { hands }\end{array}$ & $\begin{array}{l}353 \\
(31.9)\end{array}$ & 9 & $\begin{array}{l}92 \\
(37.1)\end{array}$ & $8^{*}$ & $\begin{array}{l}199 \\
(29.0)\end{array}$ & 8 & $\begin{array}{c}39 \\
(40.6)\end{array}$ & $13^{*}$ \\
\hline 1.13 Swelling of legs and arms & $\begin{array}{l}196 \\
(17.7)\end{array}$ & $33^{*}$ & $\begin{array}{c}45 \\
(18.1)\end{array}$ & $40^{*}$ & $\begin{array}{c}106 \\
(15.4)\end{array}$ & 30 & $\begin{array}{c}27 \\
(28.1)\end{array}$ & $32 *$ \\
\hline 1.14 Osteoporosis / Bone health & $\begin{array}{c}320 \\
(28.9)\end{array}$ & 12 & $\begin{array}{c}57 \\
(23.0)\end{array}$ & 32 & $\begin{array}{c}198 \\
(28.8)\end{array}$ & 9 & $\begin{array}{c}44 \\
(45.8)\end{array}$ & 6* \\
\hline 1.15 Hair and skin care issues & $\begin{array}{c}293 \\
(26.5)\end{array}$ & 17 & $\begin{array}{c}89 \\
(35.9)\end{array}$ & 10 & $\begin{array}{c}145 \\
(21.1)\end{array}$ & $19 *$ & $\begin{array}{c}38 \\
(39.6)\end{array}$ & $16^{*}$ \\
\hline 1.16 Body changes & $\begin{array}{l}246 \\
(22.2)\end{array}$ & 29 & $\begin{array}{c}68 \\
(27.4)\end{array}$ & 22 & $\begin{array}{l}127 \\
(18.5)\end{array}$ & 28 & $\begin{array}{l}34 \\
(35.4)\end{array}$ & $24 *$ \\
\hline 1.17 Bowel or bladder changes & $\begin{array}{l}281 \\
(25.4)\end{array}$ & 19 & $\begin{array}{l}66 \\
(26.6)\end{array}$ & 23 & $\begin{array}{l}159 \\
(23.1)\end{array}$ & 17 & $\begin{array}{l}34 \\
(35.4)\end{array}$ & $24^{*}$ \\
\hline 1.18 Sexual issues & $\begin{array}{r}105 \\
(9.5)\end{array}$ & 47 & $22(8.9)$ & 47 & $59(8.6)$ & 45 & $\begin{array}{c}16 \\
(16.7)\end{array}$ & $45^{\star}$ \\
\hline 1.19 Fertility issues & $71(6.4)$ & 50 & $18(7.3)$ & 49 & $41(6.0)$ & 50 & & 51 \\
\hline 1.20 Hot flashes / Menopause & $\begin{array}{c}125 \\
(11.3)\end{array}$ & 44 & $\begin{array}{c}31 \\
(12.5)\end{array}$ & 45 & $\begin{array}{c}78 \\
(11.4)\end{array}$ & 40 & $\begin{array}{c}12 \\
(12.5)\end{array}$ & $49 *$ \\
\hline $\begin{array}{l}\text { 2 Emotional } \\
\text { 2.01 Defining a new sense of normal }\end{array}$ & 220 & 30 & $\begin{array}{c}76 \\
(306)\end{array}$ & 16 & 102 & 31 & 26 & $34 *$ \\
\hline 2.02 Managing difficult emotions & $(267)$ & 25 & $\begin{array}{l}(30.0) \\
(29.0)\end{array}$ & 19 & $\begin{array}{r}137 \\
(19.9)\end{array}$ & $24 *$ & $\begin{array}{l}35 \\
(36.5)\end{array}$ & $21^{*}$ \\
\hline 2.03 Coping with grief and loss & $\begin{array}{c}193 \\
(17.4)\end{array}$ & 36 & $\begin{array}{c}53 \\
(21.4)\end{array}$ & 35 & $\begin{array}{c}93 \\
(13.5)\end{array}$ & $37 *$ & $\begin{array}{c}27 \\
(28.1)\end{array}$ & $32^{\star}$ \\
\hline 2.04 Living with uncertainty & $\begin{array}{l}317 \\
(28.6)\end{array}$ & $13^{*}$ & $\begin{array}{c}74 \\
(29.8)\end{array}$ & $17 *$ & $\begin{array}{c}173 \\
(25.2)\end{array}$ & 13 & $\begin{array}{c}44 \\
(45.8)\end{array}$ & 6* \\
\hline 2.05 Fear of recurrence & $\begin{array}{c}515 \\
(46.5)\end{array}$ & 3 & $\begin{array}{c}113 \\
(45.6)\end{array}$ & 4 & $\begin{array}{c}302 \\
(44.0)\end{array}$ & 2 & $\begin{array}{c}68 \\
(70.8)\end{array}$ & 1 \\
\hline 2.06 Managing stress & $\begin{array}{c}257 \\
(23.2)\end{array}$ & 27 & $\begin{array}{c}62 \\
(25.0)\end{array}$ & 30 & $\begin{array}{c}132 \\
(19.2)\end{array}$ & 27 & $\begin{array}{c}39 \\
(40.6)\end{array}$ & $13^{*}$ \\
\hline 2.07 Isolation / Feeling alone & $\begin{array}{c}179 \\
(16.2)\end{array}$ & 38 & $\begin{array}{c}49 \\
(19.8)\end{array}$ & $36 *$ & $\begin{array}{c}90 \\
(13.1)\end{array}$ & 39 & $\begin{array}{r}26 \\
(27.1)\end{array}$ & $34^{*}$ \\
\hline
\end{tabular}


2.08 Intimacy issues

2.09 Looking for the brighter side

2.10 Having a sense of well being

2.11 Changing relationships with spouse,

family and others

2.12 Finding support resources

2.13 Connecting to counselling services

2.14 Genetic counselling (worry about children

getting cancer)

3 Social

3.01 Managing household activities

3.02 Caring for family members

3.03 Talking about cancer with family and friends

3.04 Returning to work

3.05 Health insurance

3.06 Financial concerns

3.07 Debt from medical bills

4 Spiritual

4.01 Religious or spiritual support

4.02 Religious or spiritual distress

4.03 Loss of faith

4.04 End of life concerns

5 Others

5.01 Staying connected with the medical system

5.02 Who to call for medical problems

5.03 Keeping primary care physician informed of

cancer treatment and recurrence risk

5.04 Use of complementary or alternative therapies

5.05 Cancer treatment and recurrence risk\#

5.06 Concern about long-term effects of treatment
91 (8.2) 48

$\begin{array}{cc}286 & 18 \\ (25.8) & \\ 276 & 21 \\ (24.9) & \\ 143 & 43 \\ (12.9) & \\ 204 & 32 \\ (18.4) & \\ 113 & 45 \\ (10.2) & \\ 305 & 15 \\ (27.6) & \\ & \end{array}$

$20(8.1) \quad 48$

50 (7.3) 47

$\begin{array}{cc}82 & 13 \\ (33.1) & \\ 79 & 14 \\ (31.9) & \\ 36 & 42 \\ (14.5) & \end{array}$

$142 \quad 22$

(20.7)

$136 \quad 26$

(19.8)

70

(10.2)

42

$6328^{*}$

(25.4)

34

(13.7)

64

(25.8)

$95 \quad 36$

(13.8)

49 (7.1) 48

185

(26.9)
$14 \quad 48$

(14.6)

3424 *

(35.4)

36 19*

(37.5)

25 37*

(26.0)

2537 *

(26.0)

16 45*

(16.7)

3521 *

(36.5)

$\begin{array}{cccccccc}210 & 31 & 56 & 33 & 98 & 32 * & 34 & 24 * \\ (19.0) & & (22.6) & & (14.3) & & (35.4) & \\ 247 & 28 & 64 & 25^{*} & 121 & 29 & 34 & 24 * \\ (22.3) & & (25.8) & & (17.6) & & (35.4) & \\ 195 & 35 & 54 & 34 & 98 & 32 * & 26 & 34 * \\ (17.6) & & (21.8) & & (14.3) & & (27.1) & \\ 196 & 33^{*} & 60 & 31 & 93 & 37 * & 25 & 37 * \\ (17.7) & & (24.2) & & (13.5) & & (26.0) & \\ 327 & 11 & 92 & 8^{*} & 171 & 15 & 35 & 21^{*} \\ (29.5) & & (37.1) & & (24.9) & & (36.5) & \\ 406 & 5 & 116 & \mathbf{3} & 204 & 6 & 46 & \mathbf{5} \\ (36.7) & & (46.8) & & (29.7) & & (47.9) & \\ 280 & 20 & 78 & 15 & 140 & 23 & 32 & 30 \\ (25.3) & & (31.5) & & (20.4) & & (33.3) & \end{array}$

$\begin{array}{cccccccc}186 & 37 & 49 & 36^{*} & 97 & 34 & 20 & 43 \\ (16.8) & & (19.8) & & (14.1) & & (20.8) & \\ 85(7.7) & 49 & 13(5.2) & 50 & 48(7.0) & 49 & 15 & 47 \\ 62(5.6) & 51 & 9(3.6) & 51 & 32(4.7) & 51 & (15.6) & \\ 12 & 49 * \\ 149 & 42 & 35 & 43 & 67(9.8) & 43 & \begin{array}{c}(12.5) \\ 29\end{array} & 31 \\ (13.5) & & (14.1) & & & & (30.2) & \end{array}$

$\begin{array}{cc}331 & 10 \\ (29.9) & \\ 296 & 16 \\ (26.7) & \\ 397 & 6 \\ (35.9) & \end{array}$

$\begin{array}{cc}87 & 11 \\ (35.1) & \\ 69 & 21 \\ (27.8) & \\ 105 & 5 \\ (42.3) & \end{array}$

$172 \quad 14$

(25.0)

4011 * 16216

(23.6)

216

(31.4)

(41.7)

3816 *

(39.6)

$41 \quad 10$

(42.7)

\begin{tabular}{cccccccc}
273 & 23 & 65 & 24 & 137 & $24 *$ & 37 & 18 \\
$(24.7)$ & & $(26.2)$ & & $(19.9)$ & & $(38.5)$ & \\
566 & $\mathbf{1}$ & 126 & $\mathbf{2}$ & 330 & $\mathbf{1}$ & 64 & $\mathbf{2 *}^{*}$ \\
$(51.1)$ & & $(50.8)$ & & $(48.0)$ & & $(66.7)$ & \\
540 & $\mathbf{2}$ & 147 & $\mathbf{1}$ & 282 & $\mathbf{3}$ & 64 & $\mathbf{2 *}^{*}$ \\
$(48.8)$ & & $(59.3)$ & & $(41.0)$ & & $(66.7)$ & \\
\hline
\end{tabular}


NT, newly diagnosed, on treatment; CT, completed treatment / cancer-free $\geq 5$ years; RS, had recurrence / second cancer

${ }^{\wedge}$ Includes patients on palliative care

* Tie with at least one other issue within the patient cohort

\# New question added to the original questionnaire from Mayo clinic

Additional Table 2. Comparison of QOL scores by whether patients were concerned or very concerned with the issue of concern and cancer survivorship stage 
All^ $^{\wedge}(\mathrm{N}=1107) \quad$ NT $(\mathrm{N}=248)$

$\mathrm{CT}(\mathrm{N}=687)$

$\frac{\mathrm{C} N \mathrm{NC}}{\text { MeanMean }}$ diff

$\mathrm{C} \quad \mathrm{NC}$

$\mathrm{C} \mathrm{NC}$

(SD) (SD)

MeanMean
(SD) (SD)

MeanMean diff

$\mathrm{RS}(\mathrm{N}=96)$

1 Physical

(SD) (SD)

MearMean diff

(SD) (SD)

1.01 Pain

$\begin{array}{lll}6.3 & 7.7 & 1.4^{\star \star *}\end{array}$

$5.7 \quad 7.3 \quad 1.6^{\text {*** }}$
1.02 Fatigue

1.03 Sleep disturbances

(2.4) (1.8)

$6.47 .91 .5^{\star \star \star}$

(2.2) (1.7)

$\begin{array}{lll}6.6 & 7.6 & 1.0 * * *\end{array}$

(2.3) (1.9)

concentration

(2.3) (2.0)

1.05 Nausea / Vomiting

$\begin{array}{ll}6.4 & 7.4 \\ (2.4) & (2.0)\end{array}$

1.06 Poor appetite

6.27 .5

(2.5) (1.9)

1.07 Trouble swallowing

6.77 .3

(2.5) $(2.0)$

1.08 Mouth problems

6.87 .4

(2.3) $(2.0)$

6.57 .5

(2.4) (1.9)

1.10 Balance / Mobility

$\begin{array}{ll}6.4 & 7.6 \\ (2.4) & (1.9)\end{array}$

6.47 .7

(2.3) (1.8)

1.11 Loss of strength

$\begin{array}{lll}1.12 & \text { Numbness in feet \& } 6.8 & 7.5 \\ \text { hands } & (2.3) & (1.9)\end{array}$

1.13 Swelling of legs and 6.87 .4 arms

1.14 Bone health

(2.4) $(2.0)$

6.97 .4

(2.2) $(2.0)$

1.15 Hair \& skin care 6.87 .5 issues

1.16 Body changes

(2.1) (2.0)

6.57 .5

1.17 Bowel or bladder 6.77 .5 changes

1.18 Sexual issues

(2.3) (2.0)

7.37 .3

(2.2) (2.1)

1.19 Fertility issues

$\begin{array}{lll}7.4 & 7.3 & -0.1\end{array}$

(2.1) (2.1)

1.20 Hot flashes / 7.1 7.3 0.2 Menopause

(2.1) $(2.1)$
1.04 Memory \& $6.6 \quad 7.5$
(2.5) (1.9)

5.87 .5

(2.3) (1.9)

$6.27 .1 \quad 0.9$ **

(2.3) (2.1)

$6.07 .1 \quad 1.1^{\text {** }}$

(2.6) $(2.0)$

$5.87 .1 \quad 1.3^{\star \star}$

(2.3) (2.1)

$\begin{array}{ll}5.7 & 7.1 \\ & \end{array}$

(2.4) (2.0)

6.16 .9

(2.0) (2.2)

5.97 .0

(2.5) (2.1)

5.77 .4

(2.5) (1.8)

$\begin{array}{ll}5.8 & 7.2 \\ & \end{array}$

(2.8) (1.8)

$\begin{array}{ll}5.8 & 7.5 \\ & \end{array}$

(2.4) (1.8)

6.17 .3

(2.4) (1.9)

5.87 .1

(2.8) (1.9)

6.37 .0

(2.4) (2.1)

6.27 .2

(2.4) (2.0)

5.47 .4

(2.4) (1.9)

$6.07 .2 \quad 1.2^{\star \star}$

(2.6) (1.9)

$\begin{array}{lll}7.0 & 6.8 & -0.2\end{array}$

(2.6) (2.2)

$\begin{array}{lll}6.9 & 6.8 & -0.1\end{array}$

(2.6) (2.2)

$\begin{array}{lll}6.9 & 6.8 & -0.1\end{array}$

(2.0) (2.2) $\begin{array}{ll}6.8 & 7.9 \\ (2.1) & (1.7)\end{array}$

$6.8 \quad 8.0$

(1.9) (1.6)

$\begin{array}{lll}7.0 & 7.8 & 0.8^{\star \star \star}\end{array}$

(2.0) (1.8)

$\begin{array}{lll}7.1 & 7.8 & 0.7 * \star \star\end{array}$

(1.9) (1.8)

$\begin{array}{lll}7.2 & 7.6 & 0.4\end{array}$

(2.1) (1.8)

6.77 .7

(2.1) (1.8)

7.47 .6

(2.0) (1.9)

$\begin{array}{lll}7.3 & 7.6 & 0.3\end{array}$

(1.9) (1.9)

7.37 .7

(1.9) (1.8)

$\begin{array}{ll}7.0 & 7.8 \\ (1.8)(1.8)\end{array}$

7.07 .9

(2.0) (1.8)

7.37 .7

(1.9) (1.8)

7.47 .6

(2.0) (1.8)

7.37 .7

(1.9) $(1.9)$

7.27 .7

(1.8) (1.9)

$\begin{array}{ll}7.2 & 7.7 \\ 7.9 & 0\end{array}$

(1.9) (1.8)

7.17 .7

(1.9) (1.9)

7.97 .6

(1.7) (1.9)

7.87 .6

(1.6) (1.9)

7.57 .6

(1.7) (1.9)

$\begin{array}{lll}6.9 & 7.7 & 0.8^{\star \star \star}\end{array}$

(2.1) (1.8)

(2.0) $(2.1)$

(2.4) (2.0)

and loss

2.04 Living with 6.67 .6

uncertainty (2.3) (1.9)

2.05 Fear of recurrence $7.0 \quad 7.6$

2.06 Managing stress

(2.3) $(2.0)$

2.07 Isolation / Feeling 6.47 .5
$5.57 .31 .8^{\star \star \star}$

(2.2) (2.0)

$5.77 .11 .4^{\star \star \star}$

(2.3) (2.1)

6.97 .7

(2.0) (1.8)

6.87 .7

(2.1) (1.8)

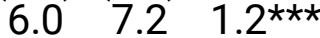

(2.2) (2.1)

6.37 .3

(2.1) (2.2)

5.77 .2

(2.1) (2.1) $\begin{array}{lll}7.0 & 7.8 & 0.8^{\star \star \star}\end{array}$

(2.1) (1.8)

7.47 .8

(1.9) (1.8)

$\begin{array}{lll}7.1 & 7.7 & 0.6^{\text {** }}\end{array}$

(2.0) (1.8)
$5.57 .6 \quad 2.1^{\text {** }}$

(2.7) (1.9)

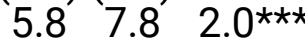

(2.6) (1.9)

$\begin{array}{lll}6.1 & 7.1 & 1.0\end{array}$

(2.8) (2.1)

$\begin{array}{lll}6.4 & 6.9 & 0.5\end{array}$

(2.9) (2.2)

$\begin{array}{lll}6.1 & 6.9 & 0.8\end{array}$

(2.9) (2.4)

$\begin{array}{lll}5.7 & 6.9 & 1.2\end{array}$

(3.4) (2.2)

$\begin{array}{lll}5.8 & 6.9 & 1.1\end{array}$

(3.7) (2.1)

$\begin{array}{lll}6.6 & 6.7 & 0.1\end{array}$

(2.7) (2.5)

$\begin{array}{lll}6.2 & 7.0 & 0.8\end{array}$

(2.9) (2.1)

$5.57 .31 .8^{\text {** }}$

(2.9) (2.0)

$5.77 .41 .7^{\text {** }}$

(2.8) (2.0)

6.07 .11 .1 *

(2.8) (2.2)

$\begin{array}{lll}6.6 & 6.7 & 0.1\end{array}$

(2.8) (2.4)

$\begin{array}{lll}6.7 & 6.8 & 0.1\end{array}$

(2.9) (2.1)

$\begin{array}{lll}6.6 & 6.7 & 0.1\end{array}$

(2.5) (2.5)

$\begin{array}{lll}6.0 & 7.0 & 1.0\end{array}$

(2.8) (2.3)

$\begin{array}{lll}5.9 & 7.1 & 1.2\end{array}$

(3.1) (2.1)

$\begin{array}{lll}5.6 & 6.8 & 1.2\end{array}$

(2.4) (2.5)

$\begin{array}{lll}5.7 & 6.7 & 1.0\end{array}$

(2.3) (2.5)

$\begin{array}{lll}5.0 & 6.9 & 1.9\end{array}$

(3.5) (2.3)

$\begin{array}{lll}5.3 & 7.32 .0 \text { * }\end{array}$

(3.4) (1.9)

$5.97 .11 .2^{\star}$

(2.8) (2.2)

$5.27 .2 \quad 2.0$ **

(3.1) (2.0)

$5.77 .51 .8^{\star \star}$

(2.9) (1.8)

$6.47 .71 .3^{*}$

(2.5) (2.1)

$5.97 .31 .4^{\star}$

(2.9) (2.0)

5.7 7.0 1.3* 
alone

(2.4) (2.0)

(2.3) (2.1)

(2.0) (1.8)

(2.9) (2.3)

2.08 Intimacy issues

6.87 .3

$6.6 \quad 6.8$

(2.1) (2.1)

(1.7) $(2.2)$

7.07 .6

$\begin{array}{lll}6.3 & 6.7 & 0.4\end{array}$

2.09 Looking for the $6.77 .50 .8^{\star \star *}$

brighter side

(2.3) (2.0)

$6.37 .10 .8^{*}$

(2.1) $(1.9)$

(3.1) (2.4)

(2.3) (2.1)

2.10 A sense of well $6.97 .40 .5^{\star \star}$ being

(2.4) (2.0)

2.11 Changing $7.0 \quad 7.3$

6.37 .0

(2.4) (2.1)

$\begin{array}{ll}6.7 & 6.8 \\ 0 & 0\end{array}$

$7.17 .70 .6^{\star \star}$

(2.0) (1.8)

5.7 7.3 1.6*

$\begin{array}{lll}7.3 & 7.7 & 0.4\end{array}$

(3.0) (1.9)

$\begin{array}{lll}6.0 & 7.1 & 1.1\end{array}$

(2.0) (1.8)

(3.1) (2.0)

$\begin{array}{lll}6.4 & 6.8 & 0.4\end{array}$

(2.0) (2.2)

2.12 Finding support $6.67 .4 \quad 0.8^{\star \star \star}$ resources

(2.5) (1.9)

2.13 Counselling services $6.7 \quad 7.4$

$5.97 .1 \quad 1.2^{\star \star}$

$\begin{array}{lll}7.3 & 7.6 & 0.3\end{array}$

(2.2) (1.8)

(2.5) (2.0)

$7.17 .70 .6^{*}$

(2.3) (1.8)

$\begin{array}{lll}7.2 & 7.6 & 0.4\end{array}$

(1.9) (2.2)

(2.3) (1.8)

$\begin{array}{lll}6.6 & 6.9 & 0.3\end{array}$

2.14 Genetic counselling $7.17 .4 \quad 0.3^{*}$

(2.1) (2.2)

$\begin{array}{lll}7.4 & 7.7 & 0.3\end{array}$

(1.9) (1.9)

(3.0) (2.3)

$\begin{array}{lll}6.5 & 6.7 & 0.2\end{array}$

(3.0) (2.3)

$\begin{array}{lll}6.1 & 6.8 & 0.7\end{array}$

(3.2) (2.4)

$\begin{array}{lll}6.3 & 6.9 & 0.6\end{array}$

(2.8) (2.4)

3 Social

3.01 Household activities $\begin{array}{lll}6.6 & 7.4 & 0.8^{\star \star \star}\end{array}$ (2.3) (2.0)

3.02 Caring for family $6.87 .40 .6^{\star \star \star}$ members

(2.4) (2.0)

3.03 Talking about cancer 6.87 .4

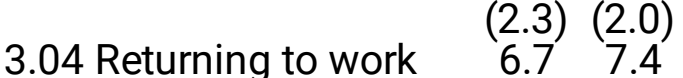

(2.2) $(2.0)$

3.05 Health insurance $\quad 6.97 .4$

(2.2) $(2.0)$

3.06 Financial concerns $6.7 \quad 7.6 \quad 0.9 * \star \star$

(2.4) (1.8)

3.07 Debt from medical $6.77 .50 .8^{\star \star \star}$ bills

(2.4) (1.9)

$6.07 .1 \quad 1.1^{\star \star}$

(2.1) $(2.2)$

$\begin{array}{lll}6.1 & 7.1 & 1.0\end{array}$

(2.3) (2.1)

$\begin{array}{lll}6.3 & 7.0 & 0.7\end{array}$

(2.0) (2.2)

$\begin{array}{lll}6.5 & 6.9 & 0.4\end{array}$

(2.2) (2.2)

$6.37 .1 \quad 0.8^{\star \star}$

(2.1) (2.1)

$6.37 .41 .1^{\star \star \star}$

(2.3) (1.8)

$6.07 .21 .2^{\star \star \star}$

(2.4) (1.9) $\begin{array}{lll}7.2 & 7.6 & 0.4\end{array}$

(1.9) (1.9)

$\begin{array}{lll}7.4 & 7.6 & 0.2\end{array}$

(1.9) (1.9)

$\begin{array}{lll}7.5 & 7.6 & 0.1\end{array}$

(1.8) (1.9)

$\begin{array}{lll}6.8 & 7.7 & 0.9 * \star \star\end{array}$

(2.0) (1.8)

$\begin{array}{lll}7.4 & 7.6 & 0.2\end{array}$

(1.9) (1.9)

7.17 .8

(2.1) (1.7)

$\begin{array}{lll}7.1 & 7.7 & 0.6^{* *}\end{array}$

(2.2) (1.7)
$5.97 .1 \quad 1.2^{*}$

(3.0) (2.1)

$5.77 .21 .5^{\star}$

(3.1) (2.0)

$5.67 .11 .5^{\star}$

(3.0) (2.1)

$\begin{array}{lll}6.3 & 6.8 & 0.5\end{array}$

(3.0) (2.3)

$\begin{array}{lll}6.8 & 6.6 & -0.2\end{array}$

(2.7) (2.4)

$\begin{array}{lll}6.6 & 6.8 & 0.2\end{array}$

(2.9) (2.0)

$\begin{array}{lll}6.9 & 6.5 & -0.4\end{array}$

(2.9) (2.3)

4 Spiritual

4.01 Religious or spiritual 7.3 $7.3 \quad 0$

support

(2.0) (2.1)

4.02 Religious or spiritual $7.2 \quad 7.3 \quad 0.1$

distress

(2.2) (2.1)

4.03 Loss of faith

$\begin{array}{lll}6.9 & 7.3 & 0.4\end{array}$

(2.6) (2.0)

4.04 End of life concerns

$6.97 .40 .5^{\star}$

(2.5) (2.0)

$\begin{array}{lll}7.2 & 6.8 & -0.4\end{array}$

(2.2) (2.2)

$\begin{array}{lll}7.0 & 6.8 & -0.2\end{array}$

(1.6) (2.2)

$\begin{array}{lll}6.0 & 6.9 & 0.9\end{array}$

(2.4) (2.2)

$\begin{array}{lll}6.6 & 6.9 & 0.3\end{array}$

(2.4) $(2.1)$ $\begin{array}{lll}7.6 & 7.6 \quad 0\end{array}$

(1.8) (1.9)

7.67 .6

(2.1) (1.9)

7.67 .6

(2.4) (1.8)

$\begin{array}{lll}7.5 & 7.6 & 0.1\end{array}$

(2.3) (1.8) $\begin{array}{lll}6.7 & 6.6 & -0.1\end{array}$

(2.9) (2.5)

$\begin{array}{lll}6.8 & 6.6 & -0.2\end{array}$

(3.0) (2.5)

$\begin{array}{lll}5.4 & 6.8 & 1.4\end{array}$

(3.6) (2.4)

$\begin{array}{lll}6.1 & 7.0 & 0.9\end{array}$

(3.0) (2.2)

5 Others

5.01 Connection with 7.2 $7.3 \quad 0.1$ medical system

(2.1) (2.1)

5.02 Who to call for $7.1 \quad 7.30 .2$

medical problems

(2.2) $(2.0)$

5.03 Keeping primary care $7.0 \quad 7.40 .4^{\star \star}$

physician

(2.2) $(2.0)$

$\begin{array}{lll}6.7 & 6.9 & 0.2\end{array}$

(2.0) (2.2)

$\begin{array}{lll}6.6 & 6.9 & 0.3\end{array}$

(2.0) (2.2)

$\begin{array}{lll}6.7 & 7.0 & 0.3\end{array}$

(2.4) $(1.9)$

$\begin{array}{lll}7.7 & 7.5 & -0.2\end{array}$

(1.8) (1.9)

$\begin{array}{lll}6.4 & 6.8 & 0.4\end{array}$

$\begin{array}{lll}7.5 & 7.6 & 0.1\end{array}$

(1.9) (1.9)

$\begin{array}{llll}7.4 & 7.7 & 0.3\end{array}$

(1.9) $(1.9)$

(2.8) (2.3)

$\begin{array}{lll}6.4 & 6.8 & 0.4\end{array}$

(2.8) (2.3)

$\begin{array}{lll}6.2 & 7.0 & 0.8\end{array}$

(2.8) (2.2)

informed

5.04 Use of $6.97 .4 \quad 0.5^{\star \star}$ complementary therapies (2.4) (2.0)

5.05 Treatment \& $7.1 \quad 7.50 .4^{\text {** }}$

recurrence risk

(2.2) (1.9)

5.06 Long-term effects of $7.07 .60 .6^{\star \star *}$

treatment

(2.1) (1.9)

$6.3 \quad 7.0 \quad 0.7 *$

(2.6) (1.9)

$\begin{array}{lll}6.7 & 7.0 & 0.3\end{array}$

(2.2) (2.1)

$\begin{array}{lll}6.5 & 7.4 & 0.9 * *\end{array}$

(2.2) (1.9)

$\begin{array}{lll}7.3 & 7.6 & 0.3\end{array}$

$\begin{array}{lll}6.6 & 6.6 \quad 0\end{array}$

(1.9) (1.9)

(2.8) (2.3)

$6.4 \quad 7.4 \quad 1.0$

(1.9) (1.8)

(2.7) (1.8)

$\begin{array}{lll}6.5 & 7.0 & 0.5\end{array}$

(2.6) (2.2) 
QOL, quality of life; SD, standard deviation; NT, newly diagnosed, on treatment; CT, completed treatment / cancer-free $\geq 5$ years; RS, had recurrence / second cancer; C, patients who were concerned or very concerned with issue; NC, patients who were not concerned, not really concerned or neither concerned nor unconcerned with issue

${ }^{\wedge}$ Includes patients on palliative care

\# See Additional Table 1 for the full description of each issue

$* 0.01 \leq p<0.05$

$\star * 0.001 \leq \mathrm{p}<0.01$

$\star \star \star p<00.001$

\section{Figures}

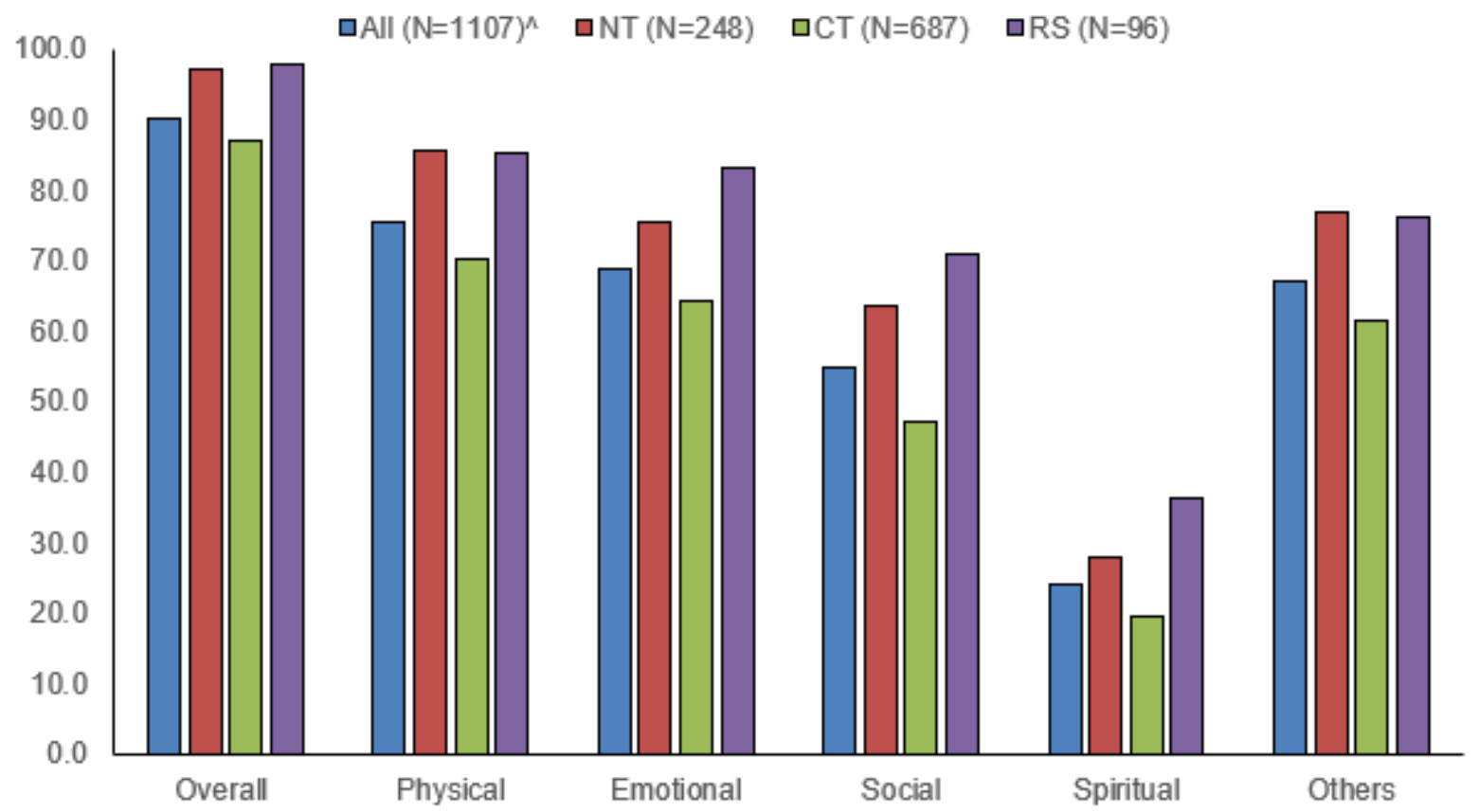

NT, newly diagnosed, on treatment; CT, completed treatment / cancer-free $\geq 5$ years; RS, had recurrence / second cancer

$\wedge$ Includes patients on palliative care

Figure 1

Patients with at least one issue of concern by domain and cancer survivorship stage 